\title{
ANALISIS INDEPENDENT INVERSION GELOMBANG PP DAN PS DENGAN MENGGUNAKAN INVERSI POST-STACK UNTUK MENDAPATKAN NILAI Vp/Vs
}

\author{
Gigih Prakoso W, Widya Utama, Firman Syaifuddin \\ Jurusan Teknik Geofisika, FTSP Institut Teknologi Sepuluh Nopember \\ e-mail: firman@geofisika.its.ac.id
}

\begin{abstract}
Abstrak. Rasio Vp/Vs merupakan parameter yang sering kali digunakan dalam interpretasi bawah permukaan jika memiliki kondisi yang kompleks (terdapat medium yang tersaturasi fluida). Akibat yang ditimbulkan dari medium yang tersaturasi fluida adalah adanya struktur-struktur bawah permukan yang tidak dapat terbaca oleh data seismik (seismik PP) sehingga menimbulkan kesulitan pada saat proses interpretasi. Untuk menghasilkan gambaran seismik yang baik, maka perlu adanya data seismik yang mampu memetakan bawah permukaan lebih baik. Gelombang seismik terkonversi (seismik PS) dapat digunakan untuk memecahkan permasalahan tersebut. Perbedaan antara gelombang seismik PP dan PS hanya terletak pada jenis gelombang yang dapat direkam oleh geophone. Jika seismik PP menggunakan source gelombang $\mathrm{P}$ dan merekam gelombang $\mathrm{P}$, namun untuk seismik $\mathrm{PS}$ menggunakan source gelombang $\mathrm{P}$ dan merekam gelombang $\mathrm{S}$. Dalam penelitian ini digunakan gelombang seismik PS dan PP untuk menghasilkan nilai Vp/Vs. Nilai Vp/Vs didapatkan dari proses inversi secara terpisah (independent inversion) antara gelombang PP dan PS. Hasil akhir yang didapatkan dari penelitian ini adalah berupa penampang $\mathrm{Vp} / \mathrm{Vs}$, sehingga dapat digunakan sebagai acuan dalam mendeskripsikan litologi bawah permukaan.
\end{abstract}

Kata Kunci: independent inversion; litologi; seismik PP; seismik PS; Vp/Vs

\begin{abstract}
The ratio of $V p / V s$ is a parameter that is often used in the interpretation of the complex subsurface condition (fluid saturated medium). The impact of fluid-saturated medium is the subsurface structures can not be seen by the seismic data (seismic PP) and causing difficulties during the process of interpretation. To produce better seismic imaging, by using seismic data that is able to interprate the subsurface better. Converted seismic waves (seismic PS) can be used to solve these problems. The difference between PP and PS seismic waves only in the types of waves that can be recorded by the geophones. If seismic PP uses source $P$ waves and record the $P$ waves, but seismic $P S$ uses source $P$ waves and record the $S$ waves. In this study seismic waves PS and PP use to generate the value of Vp/Vs. Values of Vp/Vs obtained from the inversion process separately (independent inversion) between PP and PS waves. The final result of this research is in the form of $V p / V s$ cross section, so it can be used as a reference in describing subsurface lithology.
\end{abstract}

Keywords: independent inversion; lithology; seismic PP; seismicPS; Vp/Vs

\section{PENDAHULUAN}

Seismik PS (converted wave) memberikan pengaruh yang sangat besar bagi industri minyak dan gas, terutama dengan adanya parameter $\mathrm{Vp} / \mathrm{Vs}$ yang didapatkan dari proses inversi baik secara terpisah (independent inversion) ataupun secara gabungan (joint inversion) seismik PP dan PS. Penampang $\mathrm{Vp} / \mathrm{Vs}$ akan sangat membantu dalam proses interpretasi bawah permukaan karena menggabungkan kedua sifat gelombang yang berbeda yaitu gelombang $\mathrm{P}$ dan $\mathrm{S}$, sehingga hasil interpretasi yang dihasilkan sangat baik.
Kegunaan dari nilai Vp/Vs sangat banyak, di antaranya adalah kemampuan untuk mendeteksi litologi dari sand channel (Garotta, 1985) dan batuan karbonat yang ditandai dengan variasi nilai $\mathrm{Vp} / \mathrm{Vs}$ (Miller, 1998). Selain itu, nilai Vp/Vs juga dapat digunakan dalam monitoring reservoir (Isaac, 1996). Pada kondisi bawah permukaan yang kompleks (banyak terdapat patahan), nilai $\mathrm{Vp} / \mathrm{Vs}$ juga dapat digunakan untuk memetakan struktur bawah permukan (Cary, 1999).

Pada penelitian ini, digunakan inversi seismik gelombang PP dan PS post-stack 2D untuk mendapatkan nilai perbandingan $V p$ terhadap $V s$ 
(Vp/Vs). Nilai Vp/Vs tersebut, didapatkan dari hasil inversi seismik secara terpisah (independent inversion). Sehingga, nilai $\mathrm{Vp} / \mathrm{Vs}$ tersebut dapat digunakan sebagai acuan dalam deskripsi litologi.

\section{DASAR TEORI}

\section{A. Gelombang Seismik Terkonversi}

Di dalam dunia seismik, terdapat istilah $P P$ wave dan PS wave. Dikatakan PP wave jika source yang digunakan berupa gelombang $P$ dan mode gelombang yang ditangkap oleh receiver berupa gelombang $\mathrm{P}$ atau yang lebih dikenal dengan gelombang seismik konvensional. Berbeda dengan PS wave, dikatakan PS wave jika yang ditangkap oleh receiver berupa konversi gelombang $P$ oleh bidang reflektor yaitu gelombang S. Maka dari itu, $P S$ wave dikenal dengan istilah gelombang seismik terkonversi (converted wave).

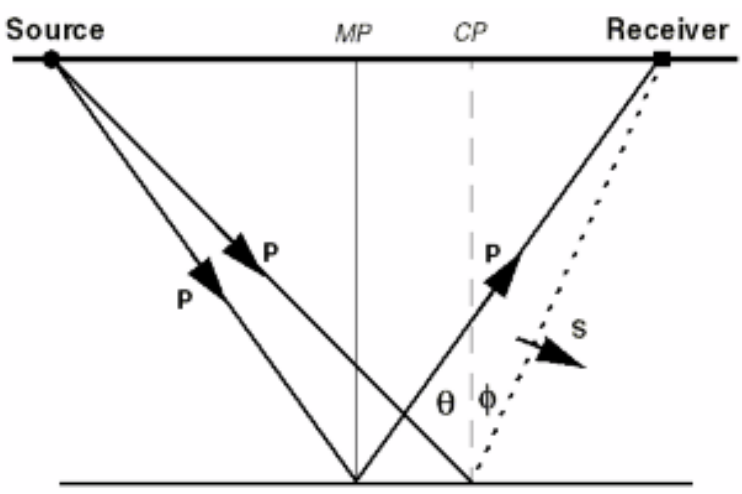

Gambar 1. Konsep Penjalaran Converted Wave (Brown, 1999).

Gambar 1 di atas merupakan konsep dari penjalaran converted wave. $\mathrm{Di}$ dalam penjalarannya, gelombang $P$ akan mencapai satu titik yang dinamakan dengan titik konversi (CP) pada batas perlapisan atau medium. Ketika gelombang $\mathrm{P}$ mencapai titik tersebut, gelombang $\mathrm{P}$ akan terkonversi menjadi gelombang upgoing $\mathrm{S}$, lalu akan terekam oleh receiver. Pada gambar di atas, sudut datang gelombang $\mathrm{P}$ dilambangkan oleh $\theta$ dan sudut pantul gelombang $\mathrm{S}$ dilambangkan oleh $\emptyset$.

\section{B. Impedansi Akustik (Zp)}

Impedansi akustik (Al) merupakan sifat batuan yang dipengaruhi oleh jenis litologi, porositas, kandungan fluida, kedalaman, tekanan, dan temperature. Oleh karenanya, maka $\mathrm{Zp}$ dapat digunakan sebagai indikator litologi, porositas, hidrokarbon, pemetaan litologi, pemetaan satuan aliran sampai dengan alat kuantifikasi karakter reservoir.

Model dasar dan yang sering digunakan dalam model satu dimensi untuk trace seismik yaitu mengacu pada model konvolusi yang menyatakan bahwa tiap trace merupakan hasil konvolusi sederhana dari reflektivitas bumi dengan fungsi sumber seismik ditambah dengan noise (Russell, 2004).

Refleksi gelombang seismik terjadi apabila terdapat perubahan impedansi akustik sebagai fungsi dari kecepatan gelombang $P$ dan densitas. Impedansi akustik didefinisikan sebagai kemampuan batuan untuk melewatkan gelombang seismik yang melaluinya. Secara fisis, impedansi akustik merupakan produk perkalian antara kecepatan gelombang kompresi dengan densitas batuan.

$$
Z p=\rho V p
$$

dengan:

$\mathrm{Zp} \quad=$ impedansi akustik (Al) $\left(\mathrm{kg} / \mathrm{m}^{3} \cdot \mathrm{m} / \mathrm{s}\right)$

$\rho \quad=\operatorname{densitas}\left(\mathrm{gr} / \mathrm{cc}\right.$ atau $\left.\mathrm{kg} / \mathrm{m}^{3}\right)$

$\mathrm{Vp} \quad=$ kecepatan $\operatorname{kompresional}(\mathrm{m} / \mathrm{s})$

Dianalogikan bahwa impedansi akustik Zp dengan acoustic hardness. Batuan yang keras (hard rock) dan sukar dimampatkan seperti batu gamping dan granit mempunyai Al yang tinggi, sedangkan batuan yang lunak seperti lempung yang lebih mudah dimampatkan mempunyai $\mathrm{Zp}$ rendah (Badley, 1985). Harga kontras Zp dapat diperkirakan dari amplitudo refleksinya, semakin besar amplitudonya semakin besar refleksinya dan kontras Zp-nya (Sukmono, 1999). 


\section{Impedansi Shear (Zs)}

Sama halnya dengan impedansi akustik, impedansi shear (Zs) juga merupakan produk dari densitas ( $\rho)$ dan kecepatan, tetapi perbedaannya dengan impedansi akustik, impedansi shear hanya bergantung pada kecepatan gelombang S. Perumusan impedansi shear dapat ditulis dengan:

$$
Z s=\rho V s
$$

dengan,

$$
\begin{array}{ll}
\mathrm{Zs} & =\text { impedansi shear }\left(\mathrm{kg} / \mathrm{m}^{3} \cdot \mathrm{m} / \mathrm{s}\right) \\
\rho & =\text { densitas }\left(\mathrm{gr} / \mathrm{cc} \text { atau } \mathrm{kg} / \mathrm{m}^{3}\right) \\
\mathrm{Vs} & =\text { kecepatan shear }(\mathrm{m} / \mathrm{s})
\end{array}
$$

Dikarenakan hanya bergantung pada gelombang $S$ yang hanya dapat merambat pada medium padat, impedansi shear tidak dapat menggambarkan fluida sehingga parameter ini hanya dapat mengukur rigiditas suatu matriks batuan. Walaupun demikian, analisa dari impedansi akustik (Al) Zp dan impedansi shear (Zs) dapat digunakan untuk memprediksikan litologi dan fluida.

\section{Inversi Seismik}

Inversi seismik merupakan suatu teknik pembuatan model bawah permukaan dengan menggunakan data seismik sebagai input dan data sumur sebagai kontrol (Sukmono, 2000). Pada dasarnya, inversi seismik merupakan proses untuk mengubah data seismik yang berupa kumpulan nilai amplitudo ke dalam kumpulan nilai impedansi akustik (AI). Perbedaan data seismik dengan data impedansi akustik adalah bahwa data seismik hanya melihat pola perlapisan bumi sedangkan data impedansi akustik melihat sifat fisik dalam lapisan itu sendiri. Oleh karena itu, tampilan impedansi akustik akan mendekati nilai riil dan lebih mudah dipahami.

Dari definisi tersebut dapat dijelaskan bahwa metode inversi merupakan kebalikan dari pemodelan dengan metode ke depan (forward modeling) yang berhubungan dengan pembuatan seismogram sintetik berdasarkan model bumi. Inversi seismik menjadi metode standar yang dikerjakan oleh geofisikawan karena mampu mendeskripsikan sifat fisik dari tiap lapisan batuan secara lebih mendetail. Penampang seismik, hanya dapat menggambarkan pola perlapisan bawah permukaan saja, berbeda dengan Al yang dapat menentukan sifat fisik dari perlapisan, seperti terlihat pada Gambar 2.

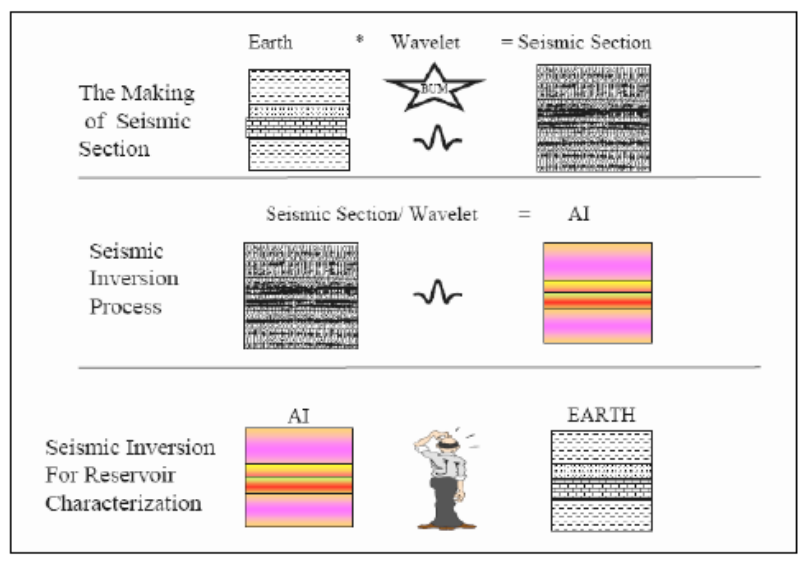

Gambar 2. Diagram Konsep Dasar Inversi Seismik (Sukmono, 2000).

Berdasarkan jenis data, metode inversi seismik dikategorikan dalam dua jenis, yaitu inversi pada data seismik yang telah dilakukan stacking (poststack inversion) dan inversi pada data yang belum dilakukan proses stacking (pre-stack inversion). Pada penelitian kali ini, inversi yang digunakan adalah inversi dengan teknik post-stack. Inversi post-stack terdiri atas inversi amplitudo dan inversi medan gelombang. Berdasarkan algoritmanya, inversi amplitudo dibedakan menjadi inversi Bandlimited, Model Based, dan Sparse Spike.

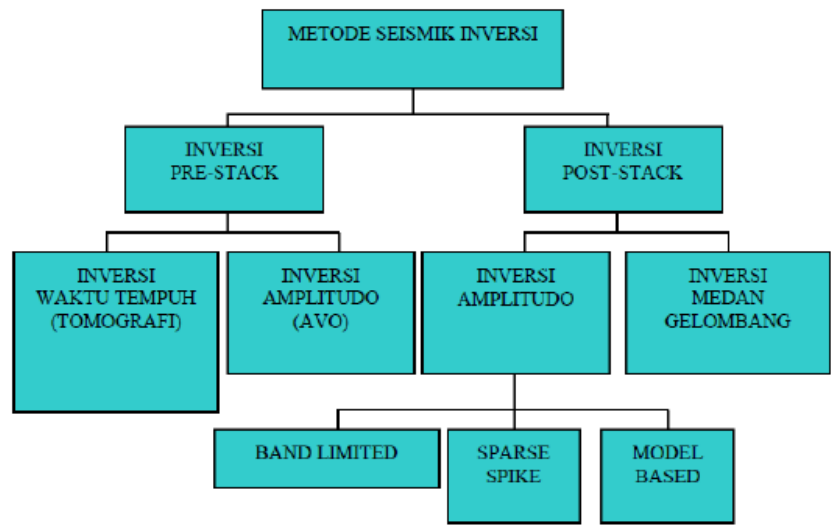

Gambar 3. Jenis-Jenis Inversi Seismik (Sukmono, 1999). 
Gambar 3 merupakan berbagai jenis teknik inversi, karena data seismik yang digunakan adalah data yang telah dilakukan proses stacking, maka teknik inversi yang digunakan dalam proses Independent Inversion adalah dengan menggunakan teknik inversi post-stack.

\section{METODOLOGI}

Proses inversi dilakukan secara terpisah baik untuk seismik PP ataupun seismik PS. Dalam penelitian ini digunakan asumsi bahwa seismik PS adalah SS sehingga hasil akhir dari proses inversi untuk masing-masing data seismik adalah berupa impedansi akustik (Zp) untuk seismik PP dan impedansi shear (Zs) untuk seismik PS. Pada alur penelitian, Gambar 4, tahapan dalam pengolahan data baik seismik PP ataupun PS adalah sama, yang membedakan adalah pada data masukan dan keluaran yang dihasilkan.

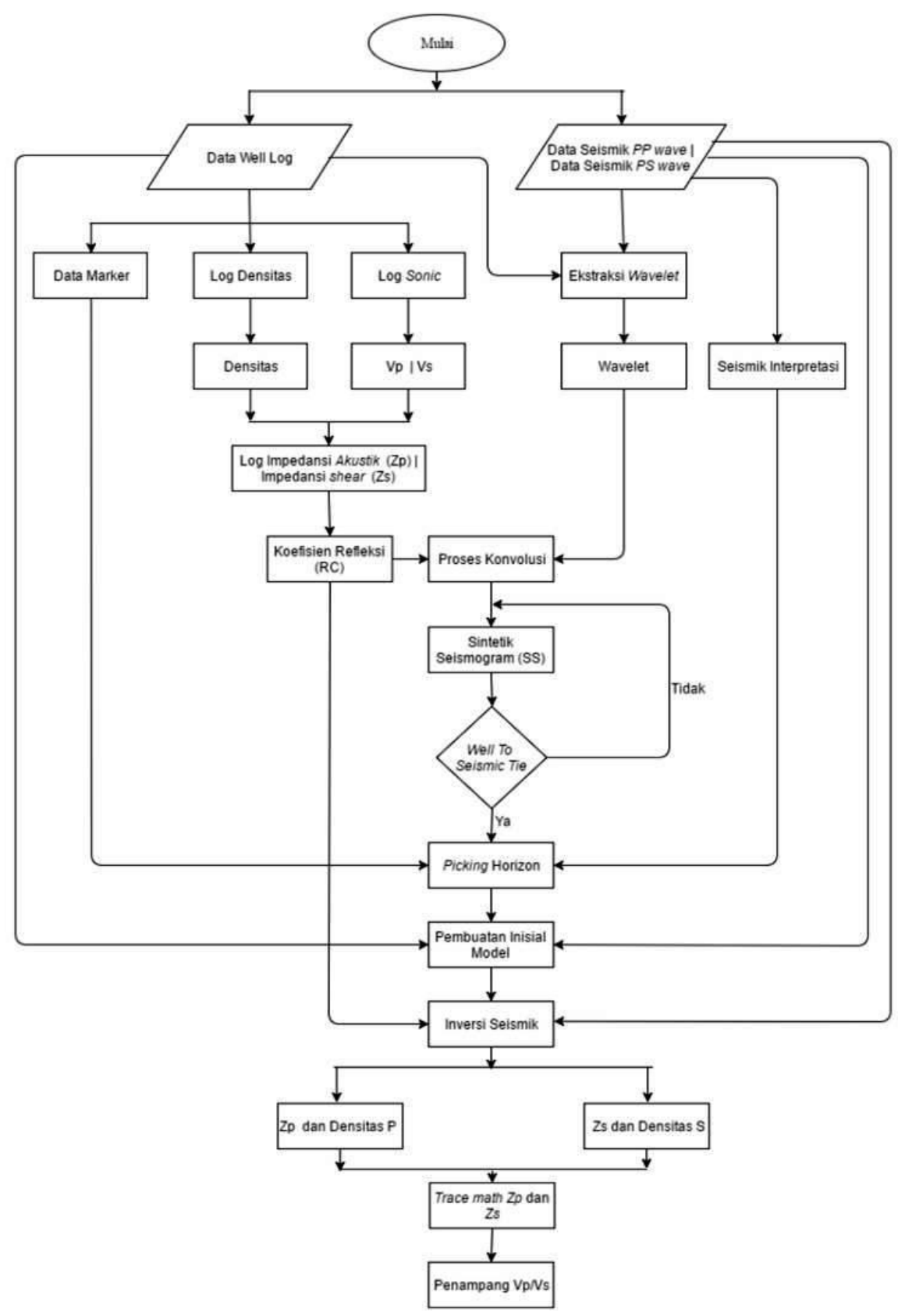

Gambar 4. Alur Kerja Penelitian. 


\section{HASIL DAN ANALISA}

\section{A. Well To Seismic Tie}

Tahapan awal yang krusial dalam proses independent inversion ini adalah proses well to seismic tie dimana pada proses ini dilakukan pengikatan data sumur dan data seismik. Didapatkan hasil korelasi sebesar 0.762 untuk PP dan 0.668 untuk PS. Wavelet yang digunakan dalam well to seismic tie adalah wavelet ricker dengan rotasi sebesar $96^{\circ}$ untuk PP dan wavelet statistical dengan rotasi sebesar $-74^{\circ}$ untuk PS. Gambar 5 merupakan korelasi pada seismik PP dan PS.

Setelah didapatkan korelasi yang sesuai, maka dilakukan picking horizon untuk masing-masing
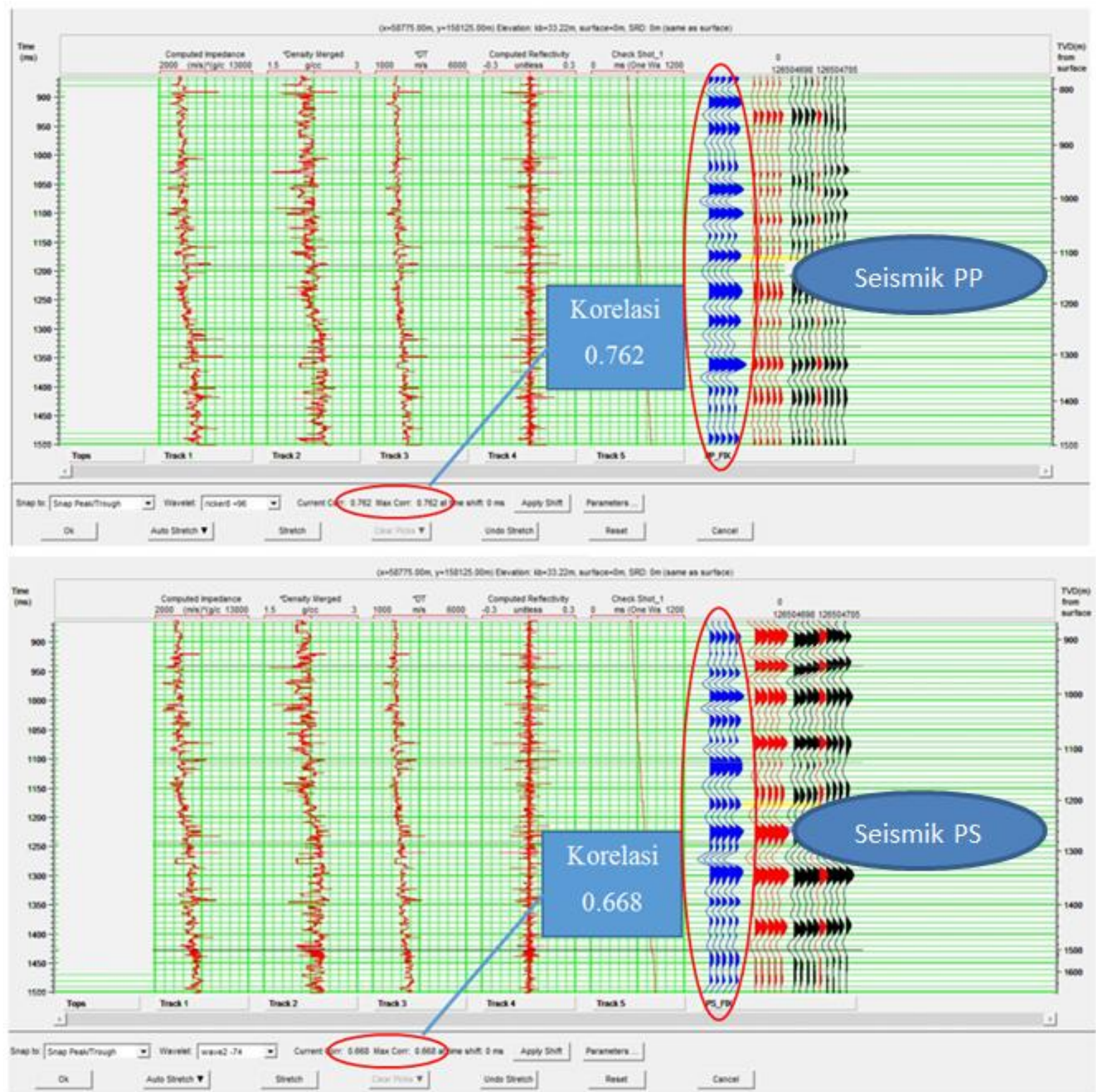

Gambar 5. Hasil Korelasi pada Seismik PP dan PS. 
seismik PP dan PS menggunakan data marker GG2 sebagai batas atas dan GG4 sebagai batas bawah dengan lebar window sebesar 1000 ms.

\section{B. Analisis Inisial Model Seismik PP dan PS}

Pembuatan inisial model sangat berpengaruh dalam hasil inversi yang diperoleh. Dalam pembuatan inisial model ini, menggunakan data dari sumur seperti impedansi akustik (Zp), log densitas, log $P$-wave dan menggunakan hasil picking horizon. Data sumur berfungsi sebagai acuan nilai impedansi, sementara data horizon digunakan sebagai panduan dalam melakukan interpolasi nilai impedansi untuk seluruh volume seismik secara lateral.
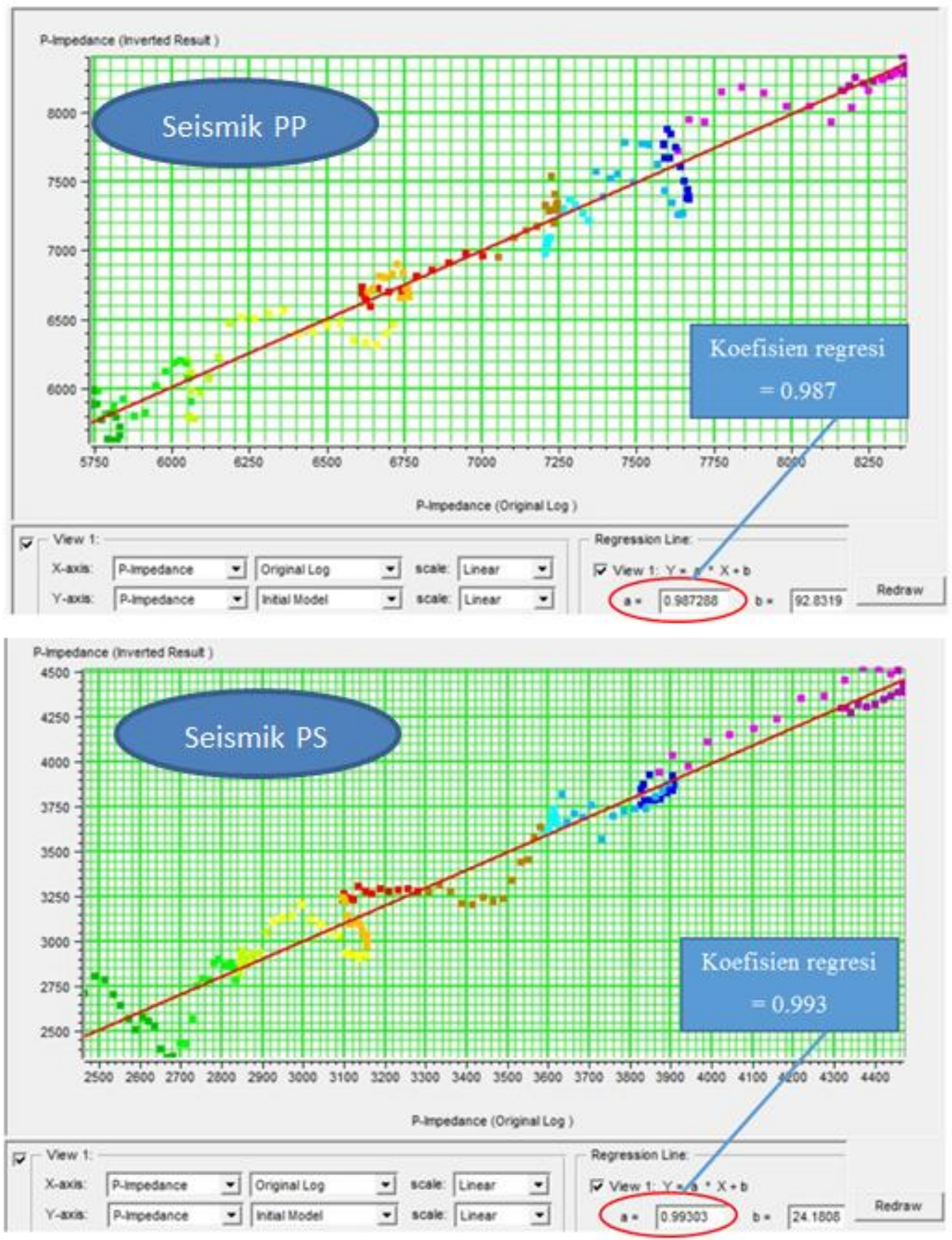

Gambar 6. Quality Control Inisial Model. 
Agar diperoleh penampang inisial model yang sesuai dan baik, maka perlu adanya qualiy control. Dalam penelitian ini, digunakan inversi analisis model base untuk mendapatkan hubungan antara data sumur dengan data inisial model. Hubungan antara data sumur dan data inisial model digambarkan dengan grafik regresi linear.
Berdasarkan Gambar 6, inisial model yang baik adalah dengan data yang tidak cenderung menyebar dan dengan koefisien regresi mendekati 1. Gambar 7 berikut ini merupakan penampang inisial model seismik PP dan PS yang digunakan dalam proses inversi.

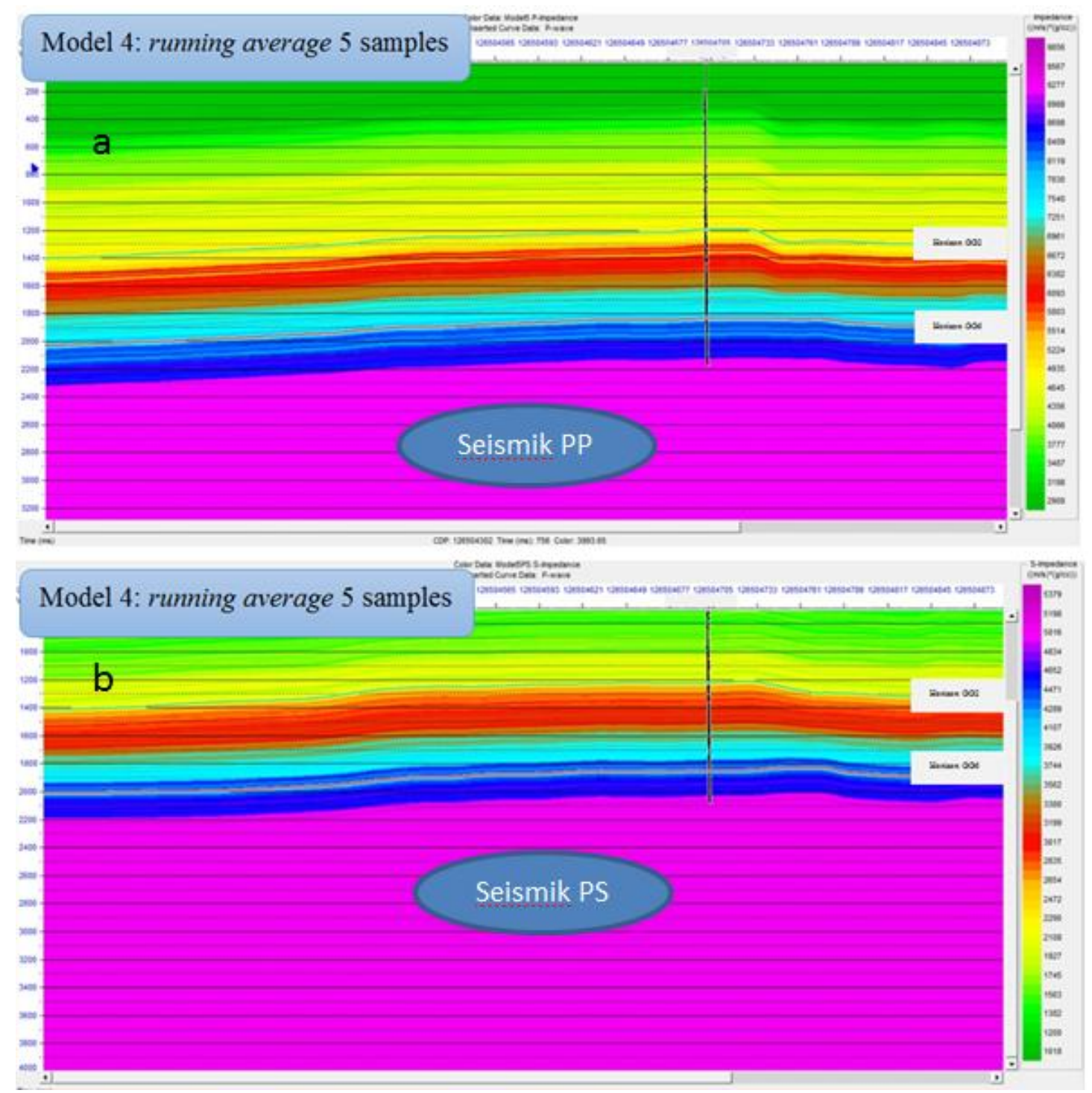

Gambar 7. Inisial Model Seismik PP dan PS.

\section{Analisis Inversi Seismik PP dan PS}

Setelah didapatkan inisial model yang paling baik, maka selanjutnya dilakukan proses inversi secara terpisah seismik PP dan seismik PS. Inversi yang dilakukan adalah dengan menggunakan inversi post-stack. Secara kuantitatif, Gambar 8 pada halaman berikut ini merupakan respon impedansi hasil inversi terhadap impedansi sumur. 

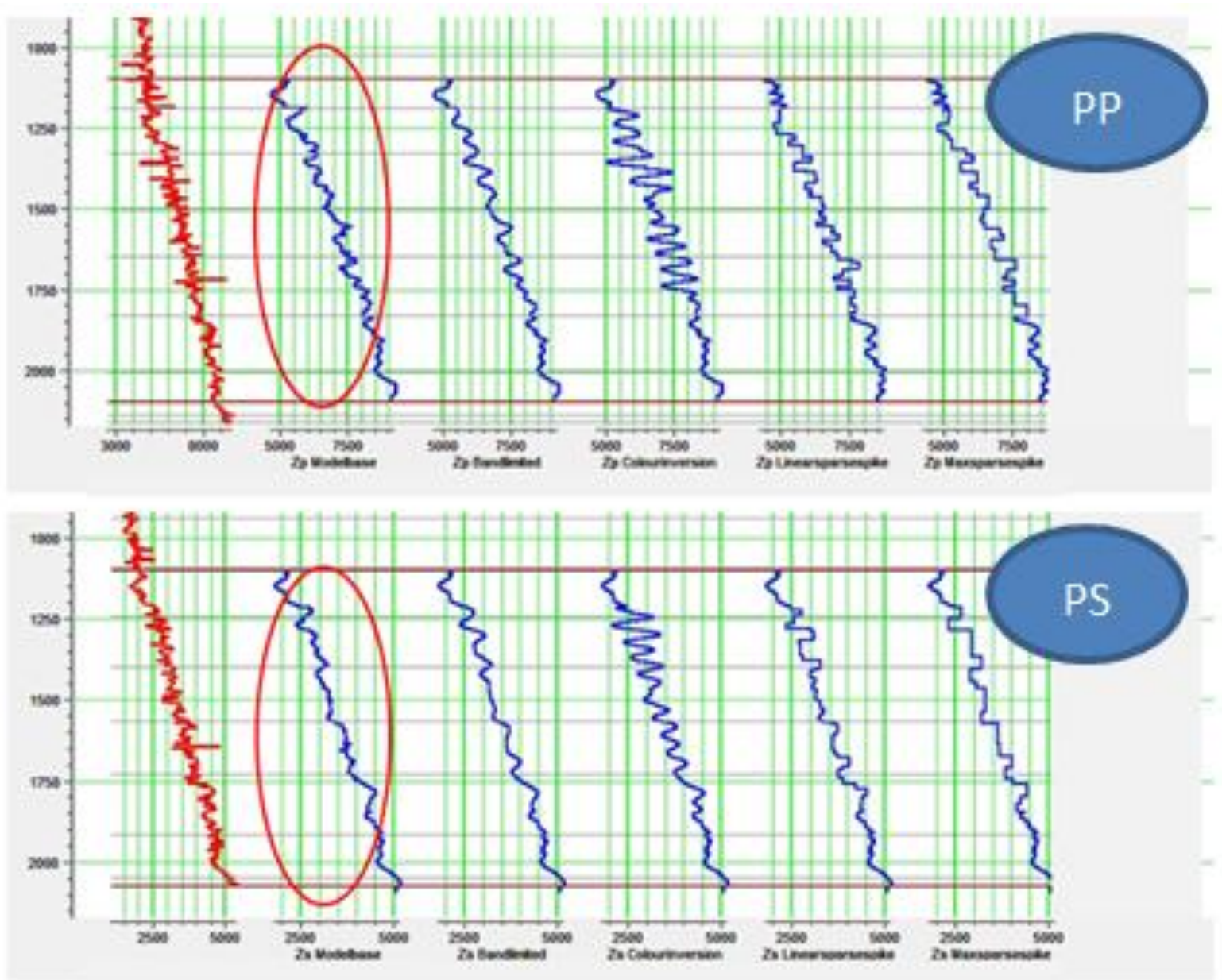

Gambar 8. Grafik Impedansi Sumur (Merah) Terhadap Impedansi Hasil Inversi (Biru).

Jika mengamati Gambar 8 di atas, terlihat bahwa grafik impedansi hasil inversi (biru) memiliki trend yang berbeda-beda, namun pada lingkaran merah (inversi model base) di atas memiliki trend yang hampir sama dengan impedansi sumur (merah). Untuk membuktikannya, dilakukan interpretasi secara kualitatif dengan mengamati error hasil inversi, korelasi, dan trend persebaran data dari grafik regresi linear antara impedansi hasil inversi dengan impedansi sumur.

Berdasarkan analisis secara kualitatif sesuai pada Gambar 9 dan 10 pada halaman berikut, dapat diamati bahwa korelasi yang didapatkan dari keempat jenis inversi di atas untuk seismik PP adalah sekitar 0.88. Untuk seismik PS didapatkan korelasi sebesar 0.96. Namun dengan menggunakan inversi model base, hasil korelasi yang didapatkan lebih tinggi dari keempat macam inversi pada Gambar 9 dan 10. Didapatkan korelasi sebesar 0.94 untuk seismik PP dan 0.97 untuk seismik PS, sehingga dalam independent inversion yang digunakan adalah inversi model base. 


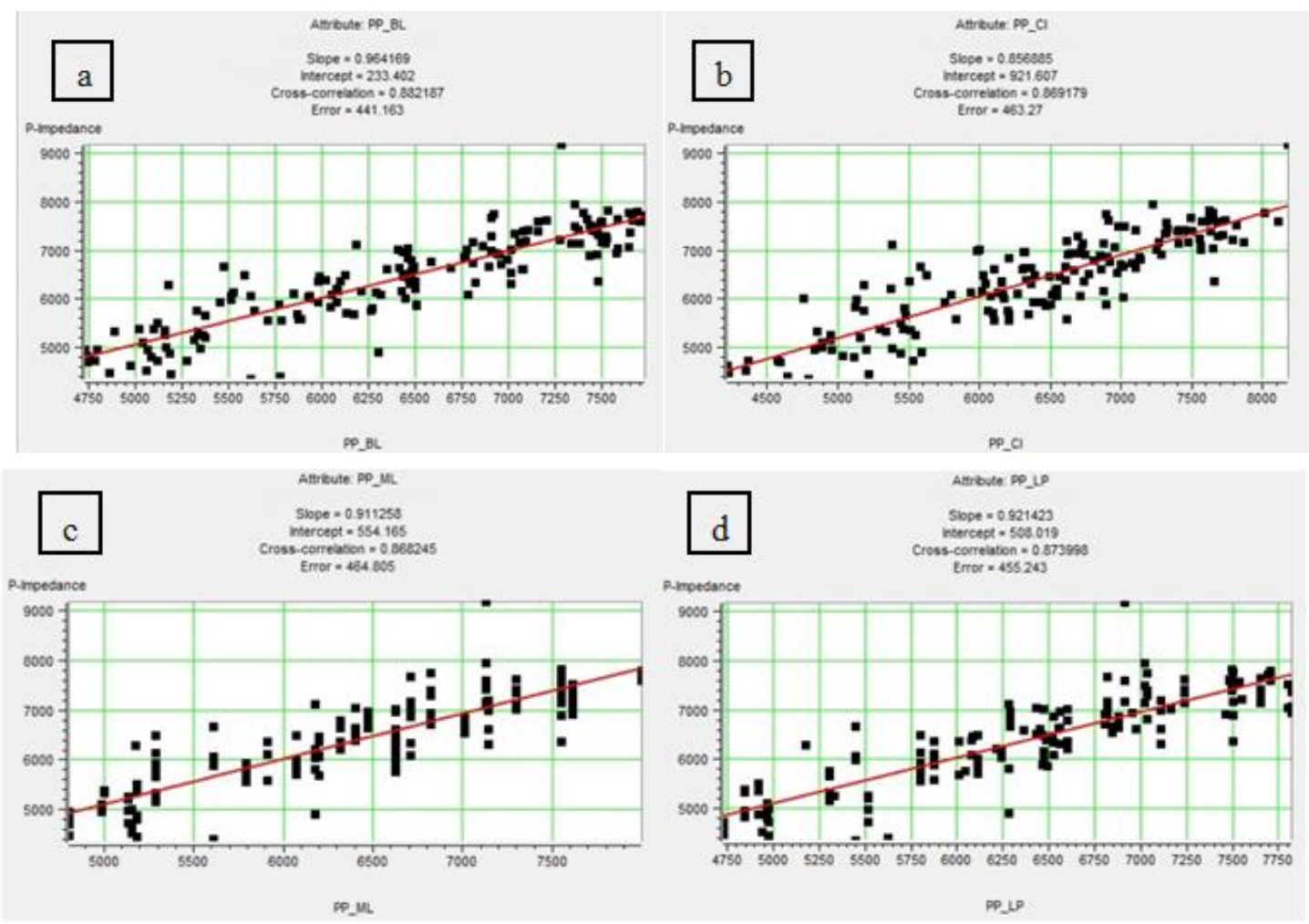

Gambar 9. Hasil Crossplot Zp Sumur dengan Zp Hasil Inversi Bandlimited (a), Colour Inversion (b), Maximum Likelihood (c), Linear Sparsespike (d).

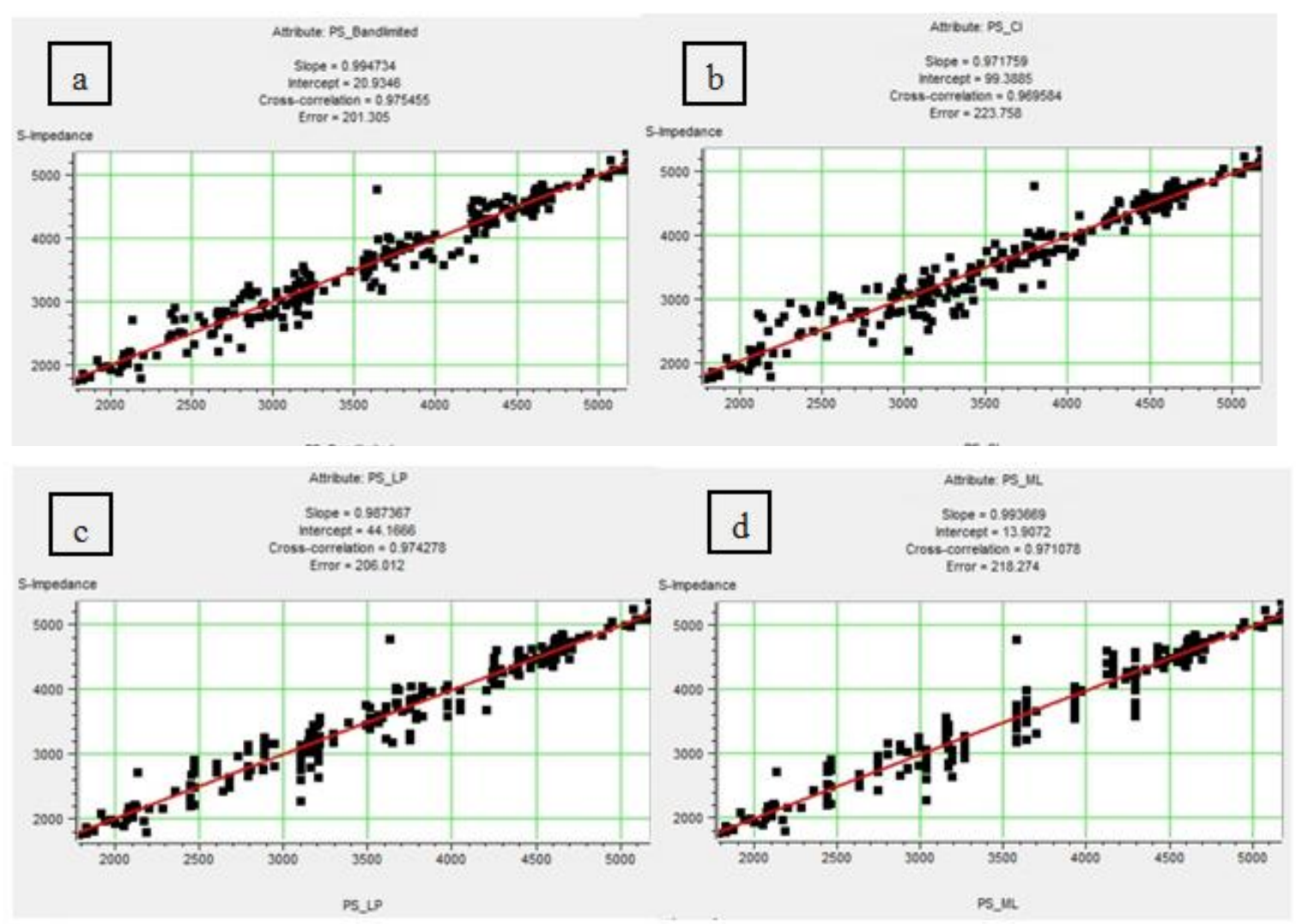

Gambar 10. Hasil Crossplot Zs Sumur dengan Zs Hasil Inversi Bandlimited (a), Colour Inversion (b), Linear Sparse Spike (c), Maximum Likelihood (d). 


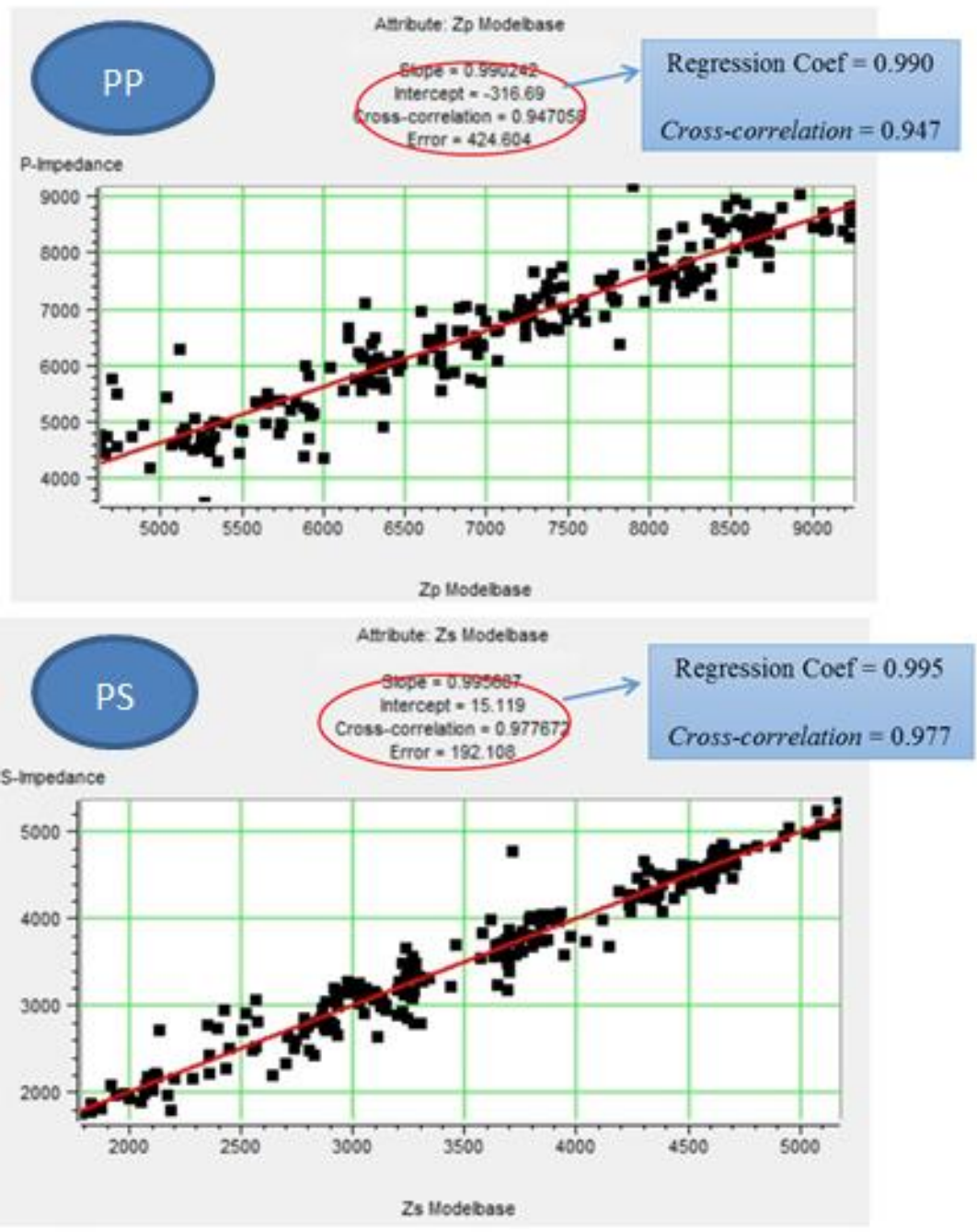

Gambar 11. Grafik Impedansi Hasil Inversi Terhadap Impedansi Sumur.

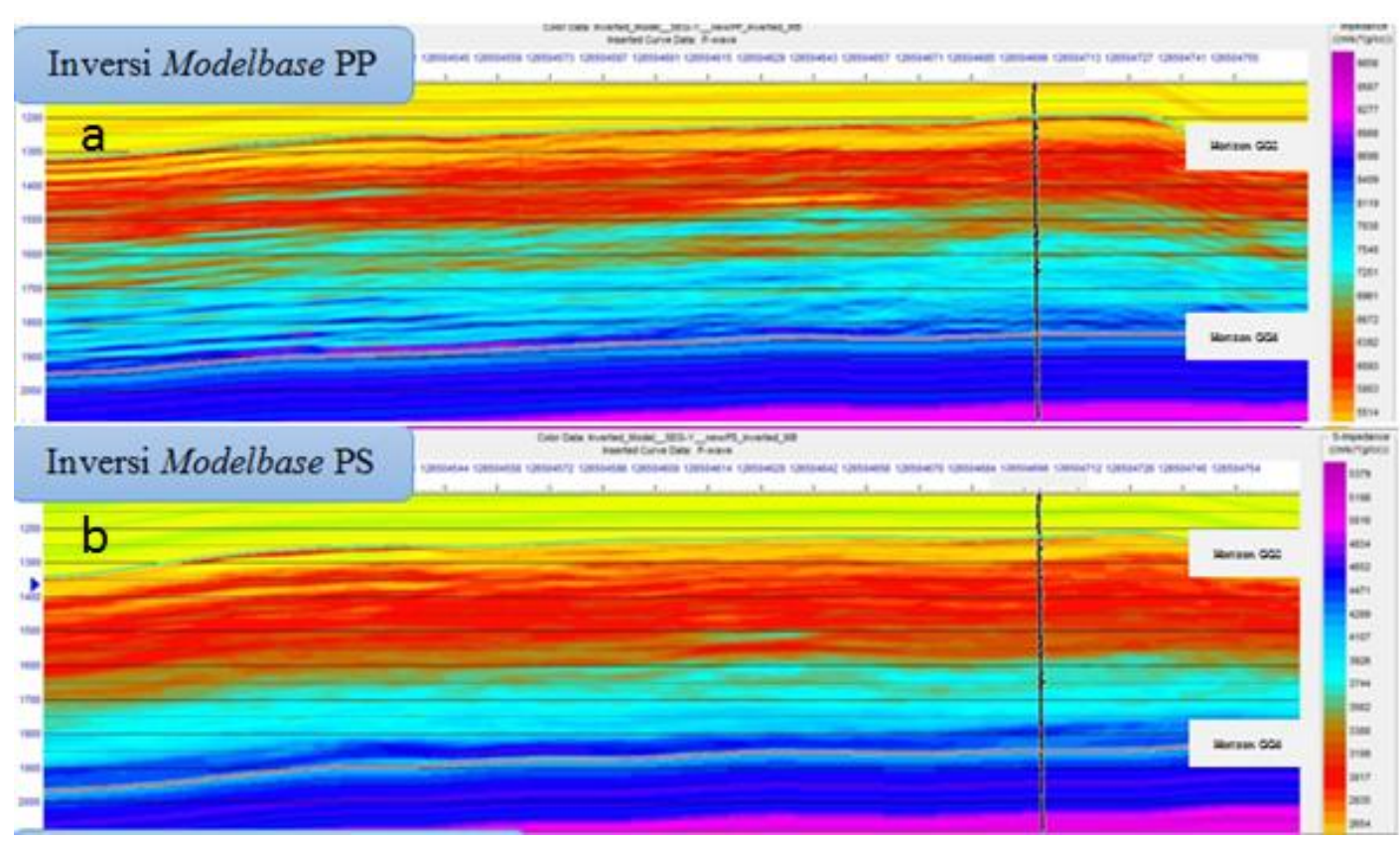

Gambar 12. Penampang Zp dan Zs Hasil Inversi. 
Gambar 12 merupakan gambaran dari penampang menggunakan inversi model base. impedansi $\mathrm{Zp}$ dan impedansi Zs dari hasil inversi

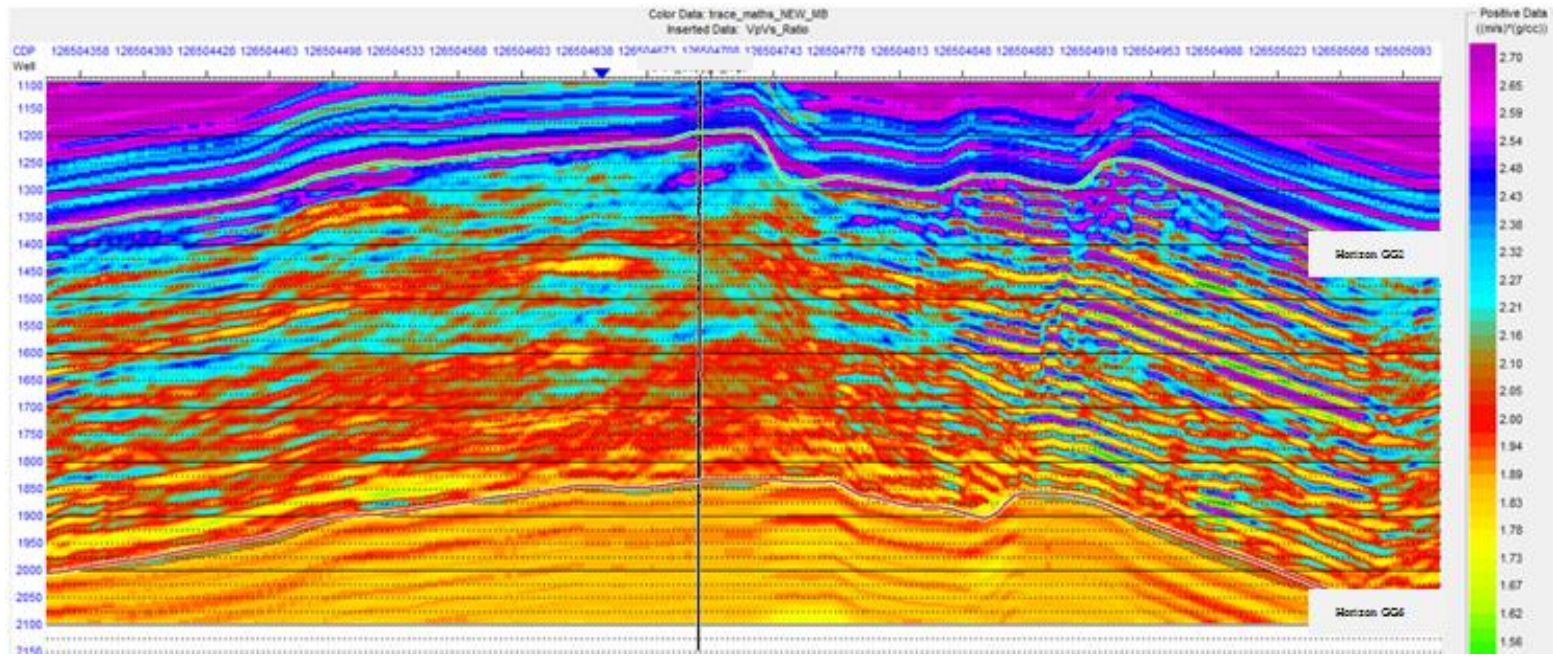

Gambar 13. Penampang Vp/Vs Hasil Independent Inversion.

\section{Rasio Vp/Vs}

Setelah mendapatkan penampang Zp dan Zs yang paling baik dari hasil inversi secara terpisah, maka dilakukan trace math antara Zp dengan $\mathrm{Zs}$ sehingga akan dihasilkan penampang $\mathrm{Vp} / \mathrm{Vs}$. Gambar 13 di atas merupakan hasil Vp/Vs yang diperoleh.
Kemudian, agar data yang dihasilkan sesuai maka dilakukan analisis secara kualitatif dengan membuat grafik regresi linear antara $\mathrm{Vp} / \mathrm{Vs}$ sumur dengan $\mathrm{Vp} / \mathrm{Vs}$ hasil inversi sebagaimana terlihat pada Gambar 14.

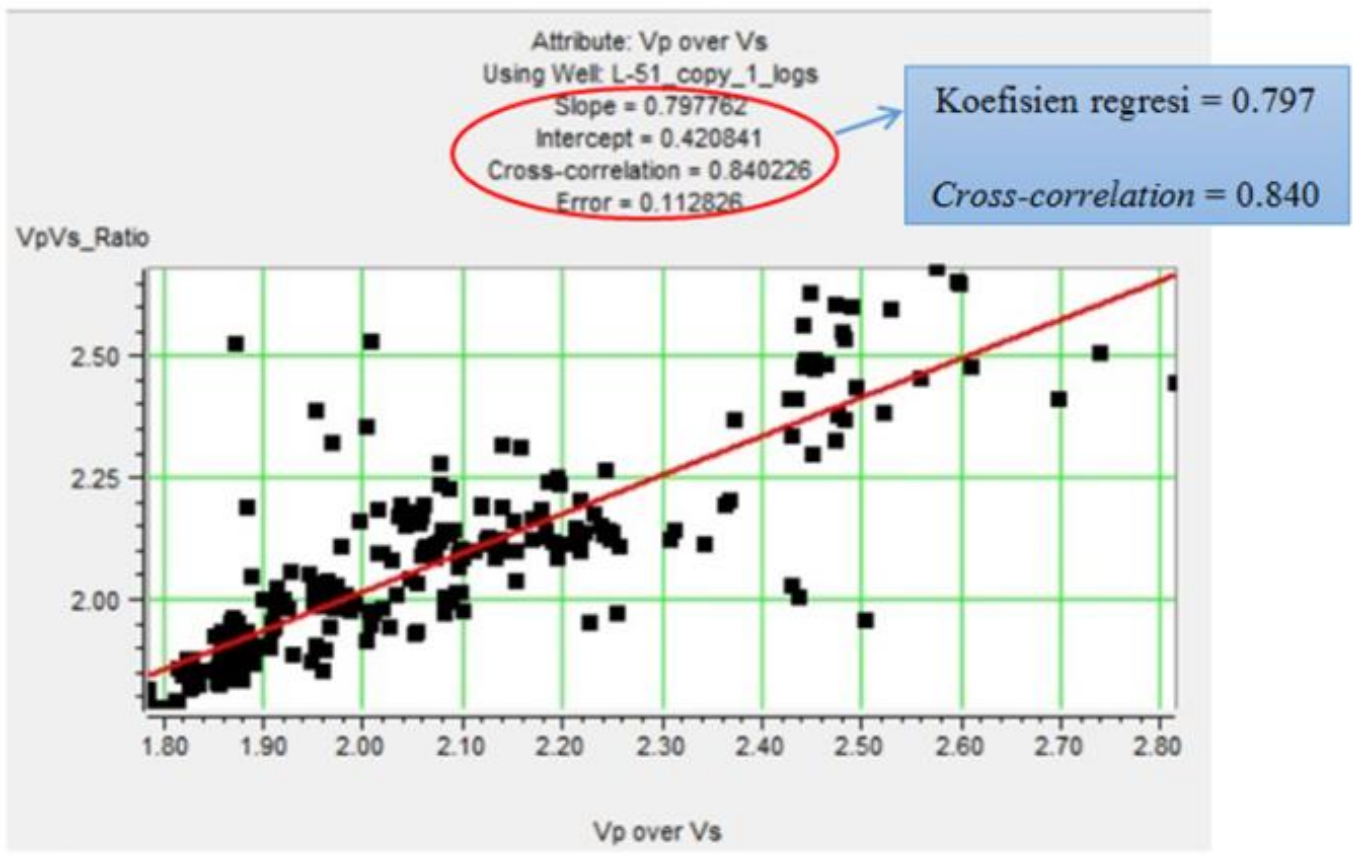

Gambar 14. Regresi Linear Vp/Vs Sumur dengan Vp/Vs Hasil Inversi. 
Dapat diamati pada Gambar 14 di atas, bahwa korelasi yang dihasilkan sudah sangat baik yaitu 0.84 sehingga penampang Vp/Vs pada Gambar 13 dapat digunakan sebagai acuan dalam menentukan litologi bawah permukaan.

\section{PENUTUP}

\section{Simpulan}

Dalam penelitian ini terdapat beberapa kesimpulan antara lain:

1. Hasil inversi secara terpisah dengan menggunakan asumsi bahwa gelombang PS adalah SS dapat diestimasi dengan menggunakan kontras impedansi S (Zs).

2. Untuk mendapatkan hasil penampang $\mathrm{Vp} / \mathrm{Vs}$ yang paling baik adalah dengan menggunakan inversi model base.

3. Quality control dalam pembuatan insial model akan menentukan hasil dari proses inversi.

\section{Saran}

Saran dari hasil dan kesimpulan untuk membangun hipotesa-hipotesa selanjutnya, antara lain perlu melakukan uji sensitivitas pada data sumur untuk mendeskripsikan litologi yang ada. Selain itu, perlu melakukan inversi gabungan (joint inversion) agar penentuan litologi menghasilkan keluaran yang baik dan terpercaya.

\section{UCAPAN TERIMA KASIH}

Penulis mengucapkan terima kasih kepada Bapak Widya Utama dan Bapak Firman Syaifuddin selaku dosen pembimbing dalam penelitian ini.

\section{DAFTAR PUSTAKA}

Brown, J., 1999. Converted-wave Seismic Exploration: A Tutorial. CREWES Research Report. Volume 11.

Cary, P. W., 1999. 3C-3D Converted-Wave Seismic. CREWES Research Report. 5, p.31.1-31.10.

Garotta, R, 1985. Observation of Shear Waves and Correlation with P Events: in Dohr, G.P., ed., Seismic Shear Waves: Part B: Applications: Geophysical Press, v. 15B.
Hampson, D., and Russell, B., 2004. AVO Theory: Hampson-Russell Software Services Ltd, Calgary.

Isaac, J. H., 1996, Seismic Methods for Heavy Oil Reservoir Monitoring. Ph.D. Thesis, The Univ. of Calgary.

Miller, S. L. M., et al., 1998. Interpretation of a Carbonate Reservoir Using P-P and P-SV Seismic Data: Submitted to Geophysics.

Sukmono, S., 1999. Seismik Atribut untuk Karakterisasi Reservoar, Laboratorium Geofisika Reservoar. Departemen Teknik Geofisika ITB, Bandung.

Sukmono, S., 2000. Seismik Inversi untuk Karakterisasi Reservoar. Jurusan Teknik Geofisika, ITB, Bandung. 